\title{
Feeding ecology, population structure and distribution of Pomatoschistus microps (Krøyer, 1838) and Pomatoschistus minutus (Pallas, 1770) in a temperate estuary, Portugal
}

\author{
R. Leitão ${ }^{\text {a,* }}$, F. Martinho ${ }^{\text {a }}$, J.M. Neto ${ }^{\text {a }}$, H. Cabral ${ }^{\text {b }}$, J.C. Marques ${ }^{\text {a }}$, M.A. Pardal ${ }^{\text {a }}$ \\ ${ }^{a}$ Institute of Marine Research (IMAR), clo Department of Zoology, University of Coimbra, 3004-517 Coimbra, Portugal \\ ${ }^{\mathrm{b}}$ Instituto de Oceanografia, Faculdade de Ciências da Universidade de Lisboa, Campo Grande, 1749-016 Lisboa, Portugal
}

Received 25 April 2005; accepted 30 August 2005

Available online 23 November 2005

\begin{abstract}
The feeding ecology, growth and spatial-temporal abundance and distribution of Pomatoschistus microps (Krøyer, 1838) and Pomatoschistus minutus (Pallas, 1770) were studied between June 2003 and June 2004, based on beam trawl surveys and macrobenthic samples conducted in the Mondego estuary, Portugal. Polychaetes, molluscs and amphipods were the most important items in the diet of $P$. microps, while for $P$. minutus the dominant preys were polychaetes, mysids and decapods. Pomatoschistus microps' recruitment lasted for six months and was composed of three new cohorts per year. Pomatoschistus minutus had an uncommon long reproductive season, from April to November, and population segregation was found, corresponding to the two reproductive peaks. Populations of both species were composed mainly of 0-group individuals with sand gobies presenting a more extended life span. In the Mondego estuary, inter- and intra-specific spatial segregation occurred between the two species and between the $0+$ and $1+$ age groups of $P$. microps.
\end{abstract}

(C) 2005 Elsevier Ltd. All rights reserved.

Keywords: Pomatoschistus; diet overlap; life cycle; competition; resource partitioning; Mondego estuary

\section{Introduction}

High fish abundance concentrated in particular areas, is a common feature in estuarine fish communities (Elliott et al., 2002). Consequently, co-occurrence of several similar morphological types (e.g. species of Soleidae, Mugilidae, Gobiidae) with overlap of ecological niches within the communities is expected. Spatial and temporal distribution, abundance patterns of fish assemblages as well as resource partitioning, are therefore, important and interesting issues for understanding the structure and dynamics of these communities (Cabral, 2000). Competition exists when the requirements of two or more individuals for a particular resource exceed the supply of that resource in the environment; or, if their demands do not exceed the supply, but they compete directly to obtain

\footnotetext{
* Corresponding author.

E-mail address: ricvl@ci.uc.pt (R. Leitão).
}

this resource. The study of diet is often used to evaluate competition between fish species (Elliott et al., 2002).

Trophic and habitat segregation are among the most important aspects of resource partitioning in fish communities but it has been difficult to assess and prove the main force behind this process (Ross, 1986a). Evidences of coexistent Gobiidae species exhibiting vertical spatial segregation, temporal segregation in spawning and absence of niche shifts when one species was temporarily absent have been reported by NorteCampos and Temming (1994). The Gobiidae is a particularly successful family in both tropical and temperate seas, well represented in estuarine and freshwater environments. Gobiidae present more than 2000 species (Bouchereau and Guelorget, 1998) and virtually all gobies exhibit demersal eggs, male parental care and highly variable number of spawnings per season (Miller, 1984).

In the Mondego estuary, four species of Gobiidae are present: Pomatoschistus microps (Krøyer, 1838), Pomatoschistus 
minutus (Pallas, 1770), Gobius niger Linnaeus, 1758, and Aphia minuta (Risso, 1810), the two Pomatoschistus species being the most abundant fishes in the Mondego estuary assemblage (Leitão et al., in press). The common goby, P. microps, is a sedentary species of semi-enclosed lagoon-like environments, which undertakes thermic migration in northern Europe (Jones and Miller, 1966). Although it is usually an annual species in the Mediterranean Sea (Bouchereau and Guelorget, 1998; Pampoulie, 2001), it can live up to two years in the northern Europe (Jones and Miller, 1966). The main food items for this fish consist of meiofauna and small macrofauna (Pihl, 1985; Salgado et al., 2004). Similarly, the sand goby, P. minutus, is a ubiquitous estuarine and inshore marine fish with a short generation time (12-18 months) being able to spend its entire life cycle within an estuary (Healey, 1971). In both species, young gobies start their life form as suprabenthic organisms, changing to epibenthic with one or two months old (Zander, 1990).

Considering the importance of these species in the marine and estuarine ecosystems (Miller, 1972), especially their role as intermediate predators in the food-web connecting microbenthos with large predator fish (Raffaelli and Milne, 1987; Raffaelli et al., 1989), few studies (Arruda et al., 1993; Salgado et al., 2004) have focused on the ecology of these species in the Atlantic coast of Southern Europe (the literature is particularly scarce for Pomatoschistus microps).

The purpose of the present study was (a) to analyze the distribution and abundance patterns of Pomatoschistus microps and Pomatoschistus minutus in a temperate estuary; (b) to compare the feeding ecology and growth of $P$. microps and $P$. minutus; and (c) to evaluate the potential for competition between the two species.

\section{Material and methods}

\subsection{Study site and sampling procedures}

The Mondego estuary is located on the Atlantic coast of Portugal $\left(40^{\circ} 08^{\prime} \mathrm{N}, 8^{\circ} 50^{\prime} \mathrm{W}\right)$ (Fig. 1). It is a small intertidal estuary, with an area of $3.4 \mathrm{~km}^{2}$, and a Mediterranean temperate climate. The estuary comprises two arms, north and south, with very different hydrologic characteristics suffering also different human impacts. The northern arm is deeper, 5$10 \mathrm{~m}$ deep at high tide (tidal range 1-3 m), highly hydrodynamic and constitutes the main navigation channel and the location of the Figueira da Foz harbour. The southern arm is shallower (2-4 $\mathrm{m}$ during high tide, tidal range $1-3 \mathrm{~m}$ ), and is characterized by large areas of intertidal flats exposed during low tide.

Fish were collected, monthly, between June 2003 and June 2004, using a $2 \mathrm{~m}$ beam trawl, with one tickler chain and $5 \mathrm{~mm}$ stretched mesh size in the cod end. Sampling was carried out during the night, at low water of spring tides, in five stations (A, B, C, D and E) (Fig. 1). Each survey consisted of three hauls, at each of the five sampling stations, in a total of 15 min per station. All fish captured were identified, measured (total length) and weighted (wet weight). Stomachs were removed and contents preserved in $4 \%$ buffered formalin for later identification. Each prey item was identified to the lowest taxonomic level possible, counted and weighted (wet weight). Temperature, salinity, $\mathrm{pH}$ and dissolved oxygen near the bottom were measured during sampling. Algae collected together with fish in beam trawl samples were also weighted (total wet weight). Each season (summer, autumn, winter and spring), sediment samples were collected using a Van Veen grab in all sampling stations, in order to determine granulometry and benthic macroinvertebrates biomass $\left(\mathrm{g} \mathrm{m}^{-2}\right.$ AFDW - ash free dry weight). Granulometry was determined after incinerating dried sediment samples at $450{ }^{\circ} \mathrm{C}$ for $7 \mathrm{~h}$, being afterwards sorted in a sieve series and weighed according to grain size.

\subsection{Feeding}

The stomach contents of 103 Pomatoschistus microps and 101 Pomatoschistus minutus were analyzed. The relative

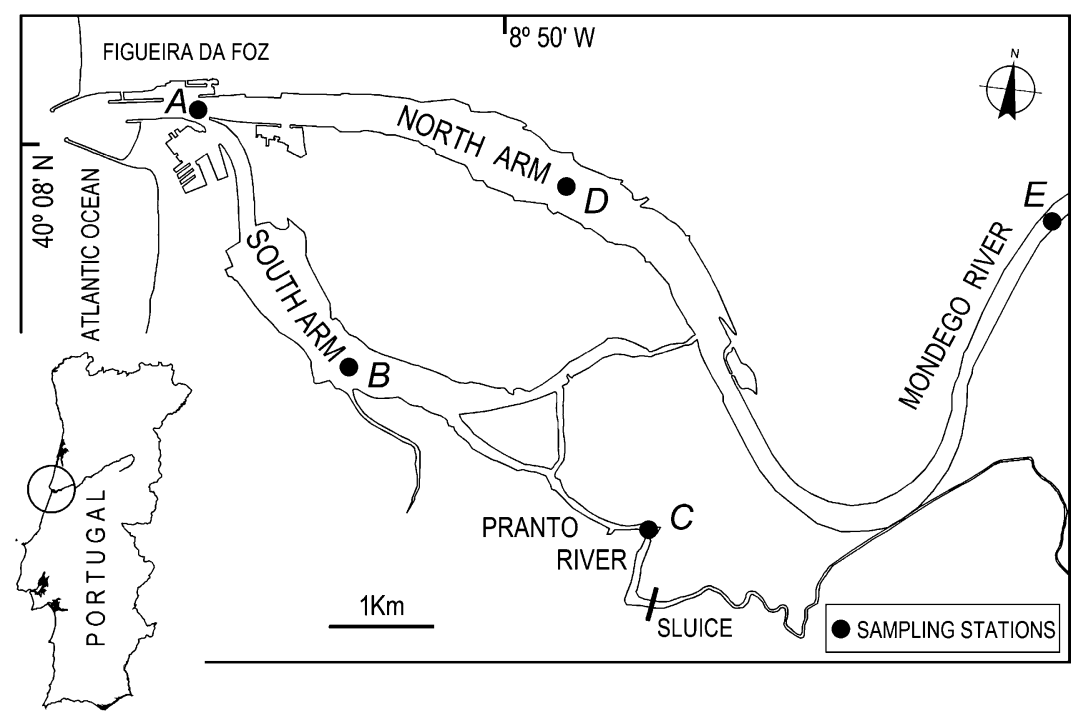

Fig. 1. Location of sampling stations within the Mondego estuary. 
importance of each prey item in the diet was expressed by three indices: the numerical index $(\mathrm{NI})$ - percentage of the number of individuals of a prey over the total number of individuals of all preys; the occurrence index (OI) - percentage of non-empty stomachs in which a prey occurred; and the gravimetric index (GI) - percentage in wet weight of a prey in relation to the total wet weight of all prey. Feeding activity was evaluated by the vacuity index defined as the percentage of empty stomachs (Hyslop, 1980). A mixed method, proposed by Hureau (1970) and adapted by Salgado et al. (2004), the dietary coefficient (QI) was also used. Defined as QI = NI $\times$ GI, this method considers both the weight and the number of ingested prey, classifying them into dominant (QI $\geq 200)$, secondary $(200>$ QI $\geq 20)$ or unimportant $(\mathrm{QI}<20)$.

Diet overlap was measured using the Schoener index (SI):

$\mathrm{SI}=1-0.5\left(\sum_{i=1}^{n}\left|p_{i_{\mathrm{A}}}-p_{i_{\mathrm{B}}}\right|\right)$

where $p_{i_{\mathrm{A}}}$ and $p_{i_{\mathrm{B}}}$ were the numerical frequencies of the item $i$ in the diet of Pomatoschistus microps and Pomatoschistus minutus, respectively (Linton et al., 1981). Values of diet overlap vary from 0 , when no food is shared, to 1 when there is the same proportional use of all food resources. Although there are no critical levels where overlap values can be compared, Wallace and Ramsay (1983) suggested that values higher than 0.6 should be considered as biologically significant.

\subsection{Population structure, growth and life span}

The available data allowed considering the hypothesis that recruitment of both Pomatoschistus species could be discontinuous. Thus, the population structure, at each moment, should correspond to a polimodal distribution of lengths. For both species, growth was estimated by tracking recognizable cohorts from successive sampling dates through size frequency distribution analysis, performed by the ANAMOD software package (Nogueira, 1992), in which the analysis consistency was tested using the $\chi^{2}$ and $G$ tests $(P=0.05)$. The algorithm of this software is based on the probability paper method, as proposed by Cassie (1963).

\subsection{Distribution and abundance patterns}

A canonical correspondence analysis was performed to evaluate spatial and temporal variation of both Pomatoschistus species, using CANOCO 4.0 (Ter Braak, 1988). This multivariate technique allows one to directly relate the pattern of community variation with the pattern of environmental variation (Ter Braak and Prentice, 1988). According to the some authors, it has several advantages when compared with other direct gradient analysis techniques, in particular when species have nonlinear and unimodal relationships to environmental gradients. Each species abundance data was averaged by age group $(0+$ and $1+)$, by sampling area (stations A, B, C, D and E) and seasons (summer, autumn, winter and spring). Temperature, salinity, dissolved oxygen, sediment type, algae cover, depth at high tide and benthic macroinvertebrates biomass were included in the analysis as environmental data.

Differences in the abundance of the two species in the Mondego estuary were evaluated using a Kruskal-Wallis test and subsequent a posteriori multiple comparisons tests.

\section{Results}

\subsection{Environmental characteristics of the sampling area}

Station A, near the mouth, had a stronger marine influence, presenting higher depth, salinity and dissolved oxygen (Table 1). Sampling stations B, C and D presented typical brackish water characteristics, with stations $B$ and $C$, adjacent to extensive intertidal areas, presenting the lowest depth. Station E, the most upstream area, was almost freshwater, with an average salinity of 1.2 (Table 1). Stations D and E, in the northern arm, registered a higher proportion of medium and large sand compared to the other sampling areas, where the sediment was mainly composed of fine sand and silt. Station C presented the highest algae biomass values, while stations A and $\mathrm{E}$ the highest benthic prey availability (Table 1).

Table 1

Mean values (SD) of water salinity, temperature, dissolved oxygen, $\mathrm{pH}$, percentage of mud, silt, fine sand, medium sand and large sand in the sediment, depth, benthic invertebrates biomass and algae cover biomass per sampling station

\begin{tabular}{|c|c|c|c|c|c|}
\hline & \multicolumn{5}{|c|}{ Sampling station } \\
\hline & A & B & $\mathrm{C}$ & $\mathrm{D}$ & E \\
\hline Salinity & $30.3(3.4)$ & $28.3(4.3)$ & $22.7(4.4)$ & $20.1(6.6)$ & $1.2(1.7)$ \\
\hline Temperature $\left({ }^{\circ} \mathrm{C}\right)$ & $15.6(2.7)$ & $17.2(3.1)$ & $18.0(5.3)$ & $16.8(3.6)$ & $17.2(5.4)$ \\
\hline $\mathrm{O}_{2}(\%)$ & $102.1(7.8)$ & $95.9(6.1)$ & $85.3(8.4)$ & $93.3(7.2)$ & $85.1(14.6)$ \\
\hline$\%$ mud & $2.3(3.4)$ & $0.7(0.7)$ & $2.1(1.4)$ & $0.0(0.0)$ & $0.1(0.1)$ \\
\hline$\%$ silt & $7.7(11.4)$ & $2.2(2.1)$ & $9.2(7.8)$ & $0.0(0.0)$ & $0.2(0.1)$ \\
\hline$\%$ fine sand & $43.6(13.1)$ & $36.3(10.0)$ & $38.8(1.1)$ & $2.0(1.6)$ & $1.3(0.2)$ \\
\hline$\%$ medium sand & $28.6(13.3)$ & $30.0(10.1)$ & $24.6(11.5)$ & $51.7(34.7)$ & $22.6(1.9)$ \\
\hline$\%$ large sand & $16.5(21.4)$ & $30.5(19.1)$ & $24.1(12.5)$ & $45.9(36.5)$ & $75.5(1.5)$ \\
\hline Depth (high tide) (m) & $8.7(1.2)$ & $2.3(0.4)$ & $2.4(1.0)$ & $5.5(0.5)$ & $4.5(0.3)$ \\
\hline Benthos $\left(\mathrm{g} \mathrm{m}^{-2}\right)$ & $0.53(2.61)$ & $0.06(0.16)$ & $0.19(0.23)$ & $0.01(0.02)$ & $0.63(1.11)$ \\
\hline Algae cover $\left(\mathrm{g} \mathrm{m}^{-2}\right)$ & $0.5(0.52)$ & $0.88(2.27)$ & $2.9(3.55)$ & $0.01(0.03)$ & $0.01(0.02)$ \\
\hline
\end{tabular}




\subsection{Feeding ecology}

Polychaeta was the most important item in the diet of both Pomatoschistus minutus (70.5\% and 59\% for NI and OI, respectively) and Pomatoschistus microps (more than 36\% for all indices) (Table 2). For P. microps, Amphipoda, Mollusca and Crustacea were the other most relevant preys, regarding NI and OI. Isopoda replaced Crustacea in importance for the gravimetric index. Concerning P. minutus diet, Mysidacea, Decapoda and Mollusca were also important prey items. Vacuity index was similar for both species: $21 \%$ for $P$. microps and $18 \%$ for $P$. minutus (Table 2). Comparing the feeding habits of two species, polychaetes were more important in the diet of $P$. minutus, while for $P$. microps the relative importance of prey items was more equable (Table 2) P. minutus also showed a wider dietary spectrum. According to the dietary coefficient (QI), polychaetes were considered a dominant prey in $P$. minutus diet and Mysidacea and Crangon crangon secondary prey. For P. microps, polychaetes, Corophium spp. and Scrobicularia plana (Da Costa, 1778) were the dominant prey items in the diet and no secondary items were found. A biologically significant diet overlapping was obtained between the two spe$\operatorname{cies}(\mathrm{SI}=0.65)$.

\subsection{Population structure, growth and life span}

Size frequency distributions of the two Pomatoschistus species were analysed in order to identify cohorts. For Pomatoschistus microps it was possible to recognise eight cohorts throughout the study period, with the recruitment of three cohorts per year, in February, April and June. For Pomatoschistus minutus five cohorts were found with the recruitment of two cohorts per year, one in spring and another during autumn. From September to February, individuals of cohort 3 were missing (Fig. 2).

Pomatoschistus microps population consisted mainly of young individuals (C3, C4 and C5 in 2003 and C6, C7 and C8 in 2004); one year old individuals represented just a small percentage of the overall population (Fig. 3). For Pomatoschistus minutus a similar pattern of population structure was found, with young individuals belonging to cohorts $\mathrm{C} 2$ and C3 dominating the population in 2003. However, from

Table 2

Relative importance of prey items in the diet of Pomatoschistus microps and Pomatoschistus minutus, according to the numerical (NI), occurrence (OI) and gravimetrical (GI) indices and the dietary coefficient (QI) (ni - non-identified material; VI - vacuity index)

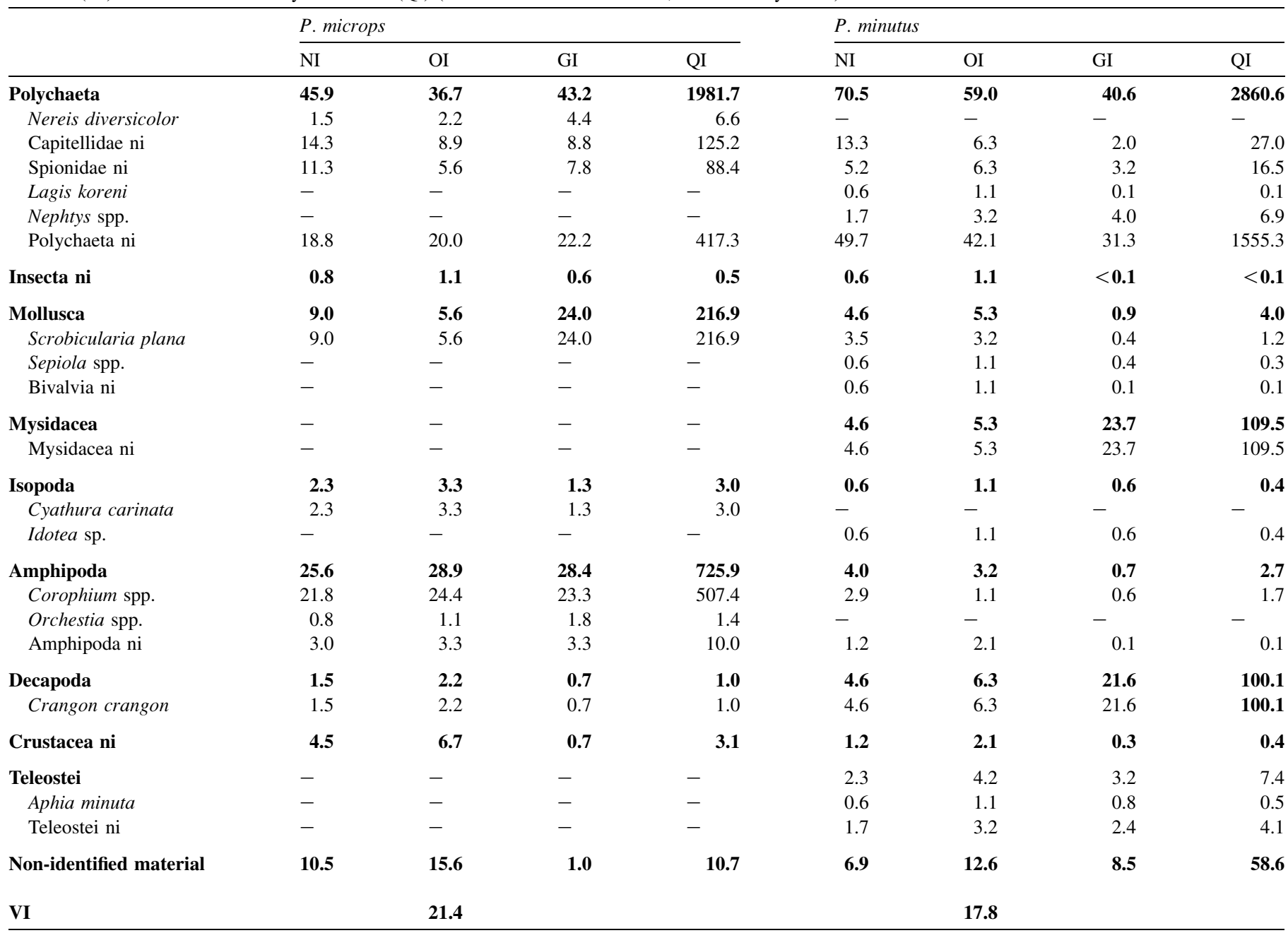


A

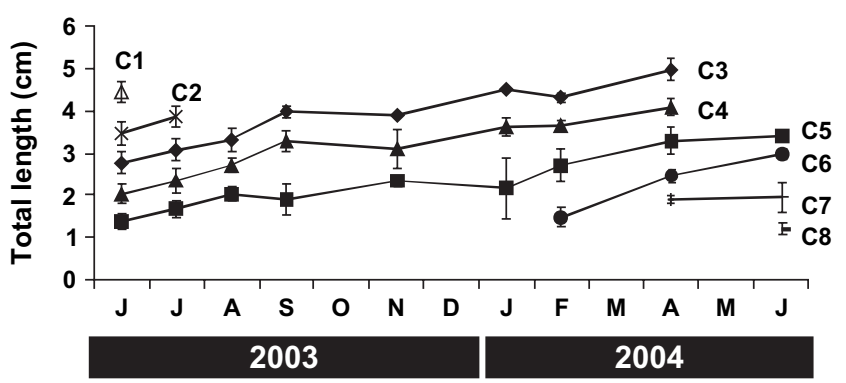

B

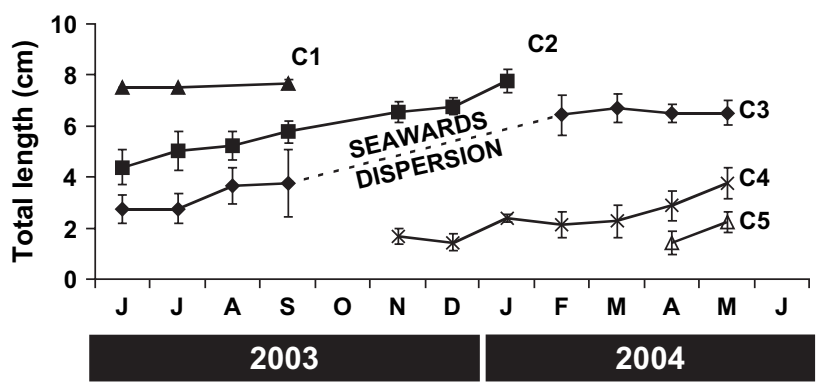

Fig. 2. Fish length variation of (A) P. microps and (B) P. minutus, for each cohort, during the study period.

September to February no individuals of cohort C3 were found, probably due to a dispersion towards the sea, being the population constituted only by cohort C2 (Figs. 2 and 3). Based on cohort analysis, life span of $P$. microps species was estimated in 16 months and for $P$. minutus this estimate varied according to the recruitment period: 16 months for

A

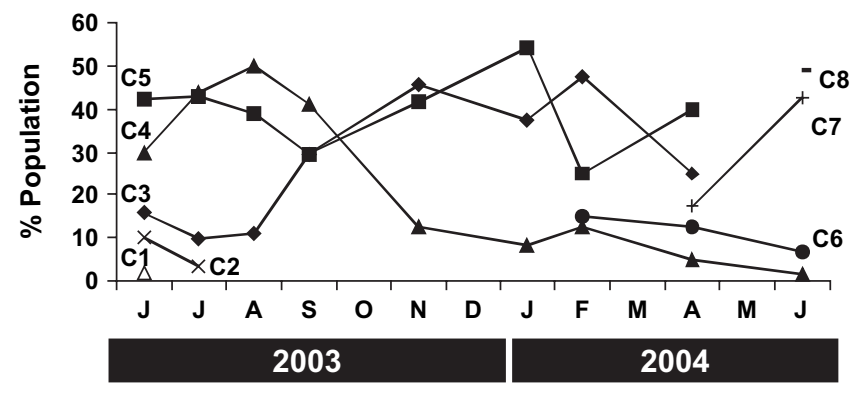

B

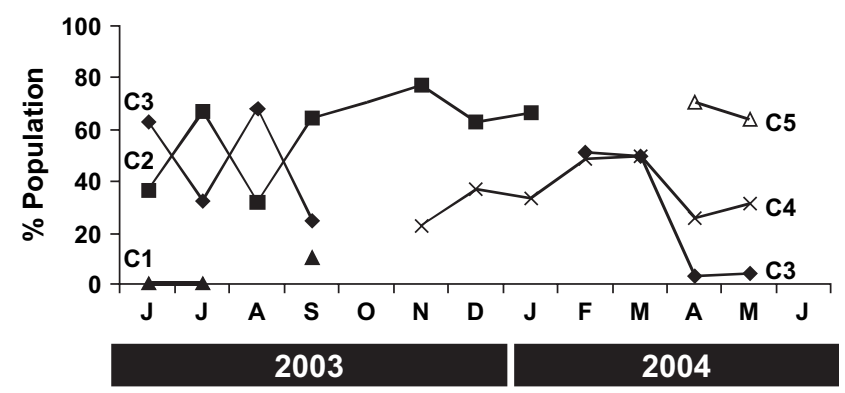

Fig. 3. Population structure of (A) P. microps and (B) P. minutus according to the percentage of individuals in each cohort. individuals that recruited in November and 20 months for individuals recruiting in April (Table 3).

It was impossible to perform sampling surveys in June 2004 at station A due to technical constraints and, therefore, cohort analysis was not performed for that particular month.

\subsection{Distribution and abundance patterns}

Both Pomatoschistus species were abundant in the Mondego estuary, with overall mean density values of 7.5 and 5.9 individuals $1000 \mathrm{~m}^{-2}$ and maximum of 102.6 and 97.3 individuals $1000 \mathrm{~m}^{-2}$ for Pomatoschistus microps and Pomatoschistus minutus, respectively. Mean size and weight values are represented in Table 4 . The common goby displayed a wider distribution, being present throughout the estuary. However, higher density values were registered in the upstream areas. On the contrary, sand goby was mainly found in the downstream areas, with higher marine influence (Fig. 4).

The first two axes of the canonical correspondence analysis (CCA) performed in order to evaluate distribution and abundance patterns, accounted for $79 \%$ of the total variance (eigenvalues of 0.54 and 0.30 , respectively) and $94 \%$ of the variance due to ecological groups - environment relations (Fig. 5). Temperature and dissolved oxygen were the environmental variables with highest magnitude, being benthic macroinvertebrates and algae biomass the weakest ones. All the other variables had similar influence. Salinity, dissolved oxygen and depth were closely associated with stations A and B and temperature with stations $\mathrm{C}$ and $\mathrm{E}$, representing the typical estuarine gradient. Three groups were found in the CCA diagram, two corresponding to different year classes of Pomatoschistus microps and one to the overall population of Pomatoschistus minutus. Pomatoschistus microps $0+$ group was found in the right edge of the diagram in association with sampling stations $\mathrm{C}$ and $\mathrm{E}$, positively correlated with temperature and coarse sand. At the right bottom of the CCA diagram, spatially distant from $0+$ group, $P$. microps $1+$ group was strongly associated with stations $\mathrm{D}$ and $\mathrm{C}$, and correlated to medium grain size of the sediment and algae biomass.

In the opposite side of the CCA diagram, Pomatoschistus minutus age groups were located together associated with stations $\mathrm{A}$ and $\mathrm{B}$ during the whole year and were positively correlated with dissolved oxygen, depth, salinity and negatively with temperature.

Pomatoschistus minutus presented significant differences in abundance for all sampling stations (Kruskal-Wallis test, $H=36.82, P<0.05$ ), while Pomatoschistus microps showed density differences between seasons (Kruskal-Wallis test, $H=13.29, P<0.05)$.

\section{Discussion}

\subsection{Feeding ecology}

Previous studies on Pomatoschistus microps diet reported that their most important prey items were polychaetes, mysids, isopods and bivalve siphons (Gee et al., 1985; Pihl, 1985; 
Table 3

Number of individuals caught per month for each Pomatoschistus species

\begin{tabular}{|c|c|c|c|c|c|c|c|c|c|c|c|c|c|c|c|}
\hline \multirow[t]{2}{*}{ Date } & \multicolumn{9}{|c|}{ P. microps } & \multicolumn{6}{|c|}{ P. minutus } \\
\hline & $\mathrm{C} 1$ & $\mathrm{C} 2$ & $\mathrm{C} 3$ & $\mathrm{C} 4$ & $\mathrm{C} 5$ & C6 & $\mathrm{C} 7$ & $\mathrm{C} 8$ & Total & $\mathrm{C} 1$ & $\mathrm{C} 2$ & $\mathrm{C} 3$ & $\mathrm{C} 4$ & $\mathrm{C} 5$ & Total \\
\hline Jun-03 & 12 & 64 & 189 & 268 & 101 & & & & 633 & 2 & 134 & 232 & & & 368 \\
\hline Jul-03 & & 11 & 146 & 143 & 32 & & & & 332 & 1 & 132 & 64 & & & 197 \\
\hline Aug-03 & & & 41 & 32 & 9 & & & & 82 & & 47 & 100 & & & 147 \\
\hline Sep-03 & & & 7 & 5 & 5 & & & & 17 & 3 & 18 & 7 & & & 28 \\
\hline Oct-03 & & & & & & & & & 4 & & 5 & & & & 5 \\
\hline Nov-03 & & & 3 & 10 & 11 & & & & 24 & & 10 & & 3 & & 13 \\
\hline Dec-03 & & & & & & & & & 12 & & 12 & & 7 & & 19 \\
\hline Jan-04 & & & 2 & 13 & 9 & & & & 24 & & 8 & & 4 & & 12 \\
\hline Feb-04 & & & 5 & 10 & 19 & 6 & & & 39 & & & 55 & 52 & & 107 \\
\hline Mar-04 & & & & & & & & & 57 & & & 13 & 13 & & 26 \\
\hline Apr-04 & & & 2 & 16 & 10 & 5 & 7 & & 40 & & & 4 & 28 & 76 & 108 \\
\hline May-04 & & & & & & & & & 13 & & & 4 & 26 & 53 & 83 \\
\hline Jun-04 & & & & & 1 & 4 & 26 & 30 & 61 & & & & & & \\
\hline Total & 12 & 75 & 395 & 497 & 197 & 11 & 7 & 30 & 1338 & 6 & 366 & 479 & 133 & 129 & 1113 \\
\hline
\end{tabular}

Norte-Campos and Temming, 1994; Salgado et al., 2004). In the present study, $P$. microps diet was similar to those described by other authors. The absence of Mysidacea is probably associated with the low abundance of this prey in the Mondego estuary. In Pomatoschistus minutus diet, polychaetes were the dominant item, followed by Crangon crangon and Mysidacea. These results corroborate those found of other authors in Europe (Zander, 1990; Norte-Campos and Temming, 1994). The only major difference is the strong dominance by polychaetes that was not reported in other studies. In the Mondego estuary, $P$. minutus occupies the downstream areas where polychaetes are abundant (Pardal et al., 1993; Cardoso et al., 2004), which may explain these differences. Pomatoschistus minutus and $P$. microps are considered opportunistic carnivores, feeding on prey according to its availability (Pihl, 1985). Moreover, the wider dietary spectrum showed by $P$. minutus was probably also associated to the areas occupied by this species, with higher marine influence and consequently higher number of species. On the other hand sand goby reach bigger sizes than common goby being able to capture larger preys.

\subsection{Population structure, growth and life span}

Based on cohort analysis, the reproductive season of Pomatoschistus microps in the Mondego estuary, was estimated approximately from December to April. This is similar with the results from other southern Atlantic European systems (Arruda

Table 4

Mean size and weight (SD) of Pomatoschistus individuals per sampling station

\begin{tabular}{llllll}
\hline Station & \multicolumn{2}{l}{ P. microps } & & & $P$. minutus \\
\cline { 2 - 3 } \cline { 6 - 6 } & Size $(\mathrm{cm})$ & Weight $(\mathrm{g})$ & & Size $(\mathrm{cm})$ & Weight $(\mathrm{g})$ \\
\hline A & $3.32(0.52)$ & $0.30(0.15)$ & & $4.67(1.07)$ & $1.19(0.76)$ \\
B & $2.72(0.41)$ & $0.13(0.08)$ & & $4.98(1.59)$ & $1.38(1.27)$ \\
C & $3.10(1.32)$ & $0.32(0.44)$ & & $7.25(0.00)$ & $2.72(0.00)$ \\
D & $3.27(0.57)$ & $0.24(1.62)$ & & $5.32(1.76)$ & $1.63(1.17)$ \\
E & $2.87(0.20)$ & $0.55(0.04)$ & & $3.80(0.00)$ & $0.22(0.00)$ \\
\hline
\end{tabular}

et al., 1993), but longer than that reported for northern estuaries (Healey, 1972; Miller, 1975; Rogers, 1988). The large number of new recruits in June (Table 3) could indicate that the reproductive effort was higher in April, in accordance with other South European estuaries (Moreira, 1989, pers. comm.; Arruda et al., 1993). Compared to Mediterranean lagoons (Pampoulie, 2001), the reproductive season was somehow shorter. Indeed, in agreement with other estuarine species (Pardal et al., 2000), P. microps presents a clinal gradient where northern Atlantic populations have a shorter reproductive season, while Mediterranean lagoons' populations, experiencing higher water temperature, have a wider reproductive season (Bouchereau and Guelorget, 1998). Temperature seems to be the main factor influencing this process, with egg survival being higher at $20{ }^{\circ} \mathrm{C}$ (Fonds and Van Buurt, 1974) and P. microps spawning preferentially at temperatures from $15{ }^{\circ} \mathrm{C}$ to $20{ }^{\circ} \mathrm{C}$ (Wiederholm, 1987).

According to the present results, first $0+$ group individuals recruited in February. Two other recruitments were also possible to distinguish, being one in April and another in June. These intermittent recruitments are probably due to fact that Pomatoschistus microps is an iteroparous species (Miller, 1984), being able to spawn several times along the reproductive

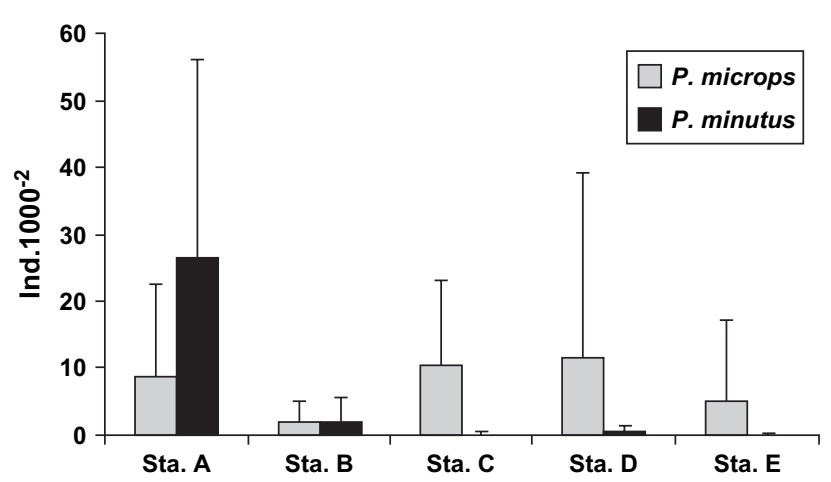

Fig. 4. Mean annual density of $P$. microps and P. minutus in the Mondego estuary, for the study period of 2003-2004. 


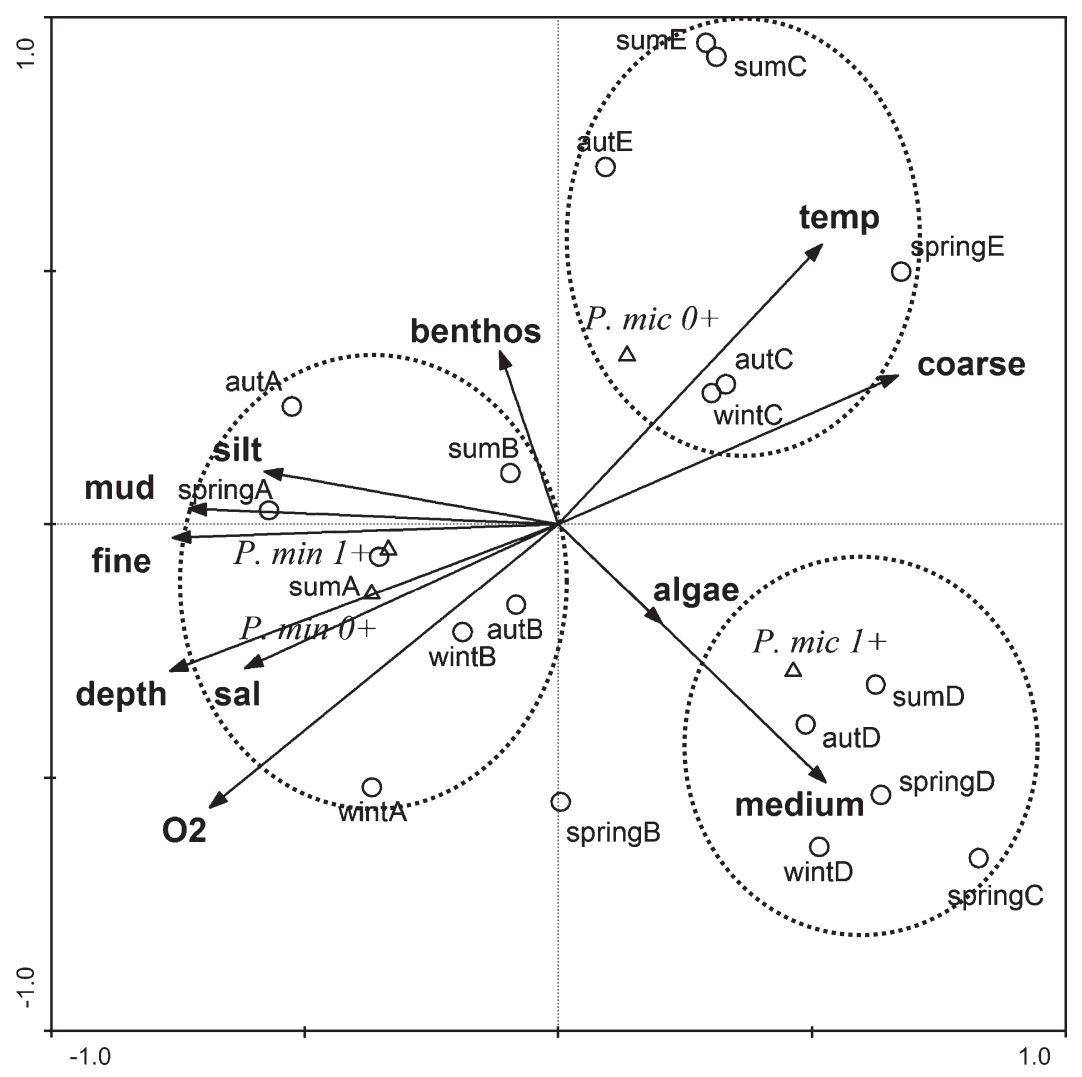

Fig. 5. Ordination diagram for the first two canonical axes of the correspondence analysis performed to fish density data (P. mic $0+-$ Pomatoschistus microps of $0+$ class; P. mic $1+-$ Pomatoschistus microps of one year class; P. min $0+-$ Pomatoschistus minutus of $0+$ class; P. min $1+-$ Pomatoschistus minutus of one year class; temp - temperature; sal - salinity; algae - algae biomass; mud $-\%$ of mud; silt $-\%$ of silt; medium $-\%$ of medium sand; coarse $-\%$ of coarse sand; fine $-\%$ of fine sand; $\mathrm{O}_{2}-$ dissolved oxygen; benthos - benthic invertebrates biomass; sum - summer; aut - autumn; wint - winter; spring - spring; A sampling station A; B - sampling station B; C - sampling station C; D - sampling station D; E - sampling station E).

season. Moreover, small variations in the environmental conditions of the Mondego estuary, as younger P. microps were found closely associated with stations $E$ and $C$, can have a synergistic effect on the intermittent recruitment. These are particularly instable areas, with station $\mathrm{E}$ being strongly influenced by freshwater discharges, while station $\mathrm{C}$ is under the influence of the Pranto River (Mondego's tributary). The common goby is a species that develops plasticity or local adaptation along its geographical distribution investing more energy in the reproduction in unpredictable environment (Pampoulie et al., 2000).

From August to January the demographic structure of the population of the common goby was composed only of $0+$ group (cohorts $\mathrm{C} 2, \mathrm{C} 3$ and $\mathrm{C} 4$ ). At the end of the reproductive season fishes of this age group were not captured, being replaced by the young-of-year. This is a typical pattern for this species in temperate estuarine systems (Arruda et al., 1993; Pampoulie, 2001).

Concerning Pomatoschistus minutus, the reproductive season was uncommonly extended, even for temperate regions, lasting from late winter (February) until August-September, and consisted of two peaks. Other studies conducted in Atlantic estuaries and coastal lagoons reported reproductive seasons with only three to five months, starting in early spring and summer (Healey, 1971; Hesthagen, 1977). The gap between these two peaks (one recruitment occurred in late winter and another in late summer), could be in a certain degree associated with the high temperatures observed in the Mondego estuary during spring and summer (Cardoso et al., 2004). Fonds and Van Buurt (1974) concluded that the sand goby is a species not so well adapted to higher temperatures, compared to the common goby. $P$. minutus eggs have higher survival rates at $10{ }^{\circ} \mathrm{C}$ than at $20{ }^{\circ} \mathrm{C}$, and above $25{ }^{\circ} \mathrm{C}$ survival is nil. Moreover, and according to the cohort analysis, in the Mondego estuary, $P$. minutus seems to disperse towards the sea. Sand goby migrations have already been described for other estuaries (Healey, 1972; Miller, 1975) and in the Mondego is probably the result of the increasing intra-specific competition for space between males born in February and other males born in the summer ( $\mathrm{C} 2$ and $\mathrm{C} 3$, respectively). At the end of summer (during the reproductive season) fishes belonging to $\mathrm{C} 3$ disperse to sea only to return in late winter probably for spawning, at the beginning of a new reproductive season. This suggests the hypothesis that in the Mondego P. minutus population is composed of two groups. If so, individuals born in August-September will spawn in late summer of the following year, living 16 months and fishes born in February will reproduce in early spring, living up to 20 months inside the estuary. Similarly, Arruda et al. (1993), who studied P. minutus in Ria de Aveiro lagoon (Portugal), found a long reproductive season (from February to August), also with two peaks. 
These authors considered that the majority of fish spawn in spring, at an age of about one year, and that the second spawning, in summer, was performed by individuals hatched in August of the previous year, resulting in a segregation in sand goby population.

Although Pomatoschistus minutus can spend its entire cycle within estuaries, it is a marine species (Healey, 1971), common in the coastal areas adjacent to the estuaries (Prista et al., 2003). In order to better understanding of its complete life cycle further studies involving simultaneous field campaigns in estuaries and in the adjacent coastal marine areas are recommended.

\subsection{Distribution and abundance patterns}

According to the spatial distribution and the CCA diagram, Pomatoschistus microps are associated with upward areas, and Pomatoschistus minutus with areas closer to the sea. Sand and common gobies present a similar niche and this spatial segregation may reduce the potential for competition. According to Schoener's index they have similar feeding habits, resulting in competition for food resources, where and whenever they become a limiting factor. Competition for food, both within and between species plays a central role in the relationships among fish, and has long been assumed to be an important factor in the structuring of fish communities (Elliott et al., 2002). However, and according to the previous authors, primary resources exploited by fishes in estuaries are space and food, and for any area it is important to determine which (if any) of this is limiting. In the Mondego estuary and according to Dolbeth et al. (2003), food is unlikely to become scarce as this is a highly productive system. It is more feasible that space, particularly during the reproductive season, will be the limiting factor. In fact, sand and common gobies are territorial species whose males build nests in which females lay their eggs. After spawning the male cares for the eggs until they hatch and the larvae start their independent pelagic life. When availability for nest sites is limited males compete intensively for these sites (Lindström, 1988; Lindström and Pampoulie, 2005). Such habitat partitioning is common within fish communities (Thorman and Wiederholm, 1983) and the alternative use of these resources within different habitats may be a way of maintaining low niche overlap. Nevertheless, these species have different ecological requirements, being $P$. minutus a less tolerant species to salinity and temperature variations, thus exhibiting more marine characteristics (Fonds and Van Buurt, 1974; Pampoulie et al., 1999). Environmental requirements were also found to be relevant in Pomatoschistus species distribution in the Mondego estuary, being difficult to access in what extent. In fact, most of the recent studies consider resource partitioning to be any substantial difference in resource use between coexisting species, realizing that differences may be due to many factors, only of which is competition (Ross, 1986b).

It is documented that Pomatoschistus species undergo ontogenic changes, such as in prey use between young-of-theyear and older stages (Salgado et al., 2004). Also, spatial segregation seems to occur between $0+$ and $1+$ groups of Pomatoschistus microps species. This habitat segregation in common goby age groups could be explained by the fact that vulnerability to predation decreases with increasing body size. Whilst smaller fish frequently use sheltered habitats to reduce the risk of predation, larger fish are often found in more unprotected areas (Elliott et al., 2002). Indeed, station $\mathrm{C}$, in the Pranto river, was found in the CCA diagram closely associated with $P$. microps $0+$ group. This area has ideal conditions for smaller fish, with high turbid waters, abundant food and extended algae cover. As a result of these considerable changes in life style, fish may occupy different niches throughout their life cycle (Elliott et al., 2002).

It is possible to conclude that individuals of Pomatoschistus microps and Pomatoschistus minutus in the Mondego estuary tend to occupy different areas reducing the potential for competition among them. However, further studies are required to find in what extent the relationships with other abundant fish species in the estuary (e.g. flounder and sea bass) affect these populations, to understand their life cycle local adaptations and to whether their distribution in the estuary is exclusively a result of different environmental requirements or does inter-specific competition play an important role?

\section{References}

Arruda, L.M., Azevedo, J.N., Neto, A.I., 1993. Abundance, age-structure and growth, and reproduction of Gobies (Pisces; Gobidae) in the Ria de Aveiro Lagoon (Portugal). Estuarine, Coastal and Shelf Science 37, 509-523.

Bouchereau, J.L., Guelorget, O., 1998. Comparison of three Gobiidae (Teleostei) life history strategies over their geographical range. Oceanologica Acta 24, 503-517.

Cabral, H.N., 2000. Distribution and abundance patterns of flatfishes in the Sado estuary, Portugal. Estuaries 23, 351-358

Cardoso, P.G., Pardal, M.A., Lillebø, A.I., Ferreira, S.M., Raffaeli, D., Marques, J.C., 2004. Dynamic changes in seagrass assemblages under eutrophication and implications for recovery. Journal of Experimental Marine Biology and Ecology 302, 233-248.

Cassie, R.M., 1963. Tests of significance for probability paper analysis. New Zealand Scientific Review 6, 474-482.

Dolbeth, M., Pardal, M.A., Lillebø, A.I., Azeiteiro, U., Marques, J.C., 2003. Short- and long-term effects of eutrophication on the secondary production of an intertidal macrobenthic community. Marine Biology 143, 12291238.

Elliott, M., Hemingway, K.L., Costello, M.J., Duhamel, S., Hostens, K., Labropoulou, M., Marshall, S., Winkler, H., 2002. Links between fish and other trophic levels. In: Elliot, M., Hemingway, K. (Eds.), Fishes in Estuaries. Blackwell Science, United Kingdom, pp. 54-123.

Fonds, M., Van Buurt, G., 1974. The influence of temperate and salinity on development and survival of goby eggs (Pisces, Gobiidae). Hydrobiology Bulletin 8, 110-116.

Gee, J.M., Warwick, R.M., Davey, J.T., George, C.L., 1985. Field experiments on the role of epibenthic predators in determining prey densities in an estuarine mud flat. Estuarine, Coastal and Shelf Science 21, 429-448.

Healey, M.C., 1971. Gonad development and fecundity of the sand goby, Gobius minutus Pallas. Transactions of the American Fisheries Society 3, 520-526.

Healey, M.C., 1972. On the population ecology of the common goby in the Ythan estuary. Journal of Natural History 6, 133-145.

Hesthagen, I.H., 1977. Migration, breeding and growth in Pomatoschistus minutus (Pallas) (Pisces, Gobiidae) in Oslofjorden, Norway. Sarcia 63, 17-26. 
Hureau, J.C., 1970. Biologie comparée de quelques poisons antarctiques (Nototheniidae). Buletin de l'Institut Océanographique de Monaco 68, 885-890.

Hyslop, E.J., 1980. Stomach contents analysis: a review of methods and their application. Journal of Fish Biology 17, 415-429.

Jones, D., Miller, P.J., 1966. Seasonal migration of the common goby, Pomatoschistus microps (Krøyer), in Morecamb Bay. Hydrobiologia 27, 515528.

Leitão, R., Martinho, F., Jorge, I., Cabral, H., Marques, J.C., Pardal, M.A. The fish assemblage of the Mondego estuary: composition, structure and trends over the past two decades. Hydrobiologia, in press.

Lindström, K., 1988. Male-male competition for nest sites in the sand goby, Pomatoschistus minutus. Oikos 53, 67-73.

Lindström, K., Pampoulie, C., 2005. Effects of resource holding potential and resource value on tenure at nest sites in sand gobies. Behavioural Ecology 16, 70-74.

Linton, L.R., Davies, R.W., Wrona, F.J., 1981. Resource utilization indices an assessment. Journal of Animal Ecology 50, 283-293.

Miller, P.J., 1972. The identity of Gobius affinis Kolombatovic, with notes on the systematics and biology of Pomatoschistus pictus (Malm). Annuali del Museo civico di Storia Naturale "Giacomo Doria" 79, 53-88.

Miller, P.J., 1975. Age-structure and life-span in the common goby, Pomatoschistus microps. Journal of Zoology of London 177, 425-448.

Miller, P.J., 1984. The tokology gobioid fishes. In: Potts, G.W., Wootton, J.R. (Eds.), Fish Reproduction: Strategies and Tactics. Academic press, London, United Kingdom, p. 256.

Moreira, F.M., 1989. Alguns aspectos de taxonomia, crescimento e reprodução de Pomatoschistus minutus (Pallas, 1770) e Pomatoschistus microps (Krøyer, 1838) (Pisces, Gobiidae) na parte superior do estuário do Tejo, personal comment.

Nogueira, A.J.A., 1992. ANAMOD - extracção dos componentes modais de distribuições de frequências de variáveis biométricas. Manual. Department of Zoology, University of Coimbra.

Norte-Campos, A.G.C., Temming, A., 1994. Daily activity, feeding and rations in gobies and brown shrimp in the northern Wadden Sea. Marine Ecology Progress Series 115, 41-53.

Pampoulie, C., Rosecchi, E., Bouchereau, J.L., Crivelli, A.J., 1999. Life history traits of Pomatoschistus minutus (Teleostei, Pisces) in the Rhône Delta, France. Journal of Fish Biology 55, 892-896.

Pampoulie, C., Bouchereau, J.L., Rosecchi, E., Poizat, G., Crivelli, A.J., 2000. Annual variations in the reproductive traits of Pomatoschistus microps in a Mediterranean lagoon undergoing environmental changes: evidence of phenotypic plasticity. Journal of Fish Biology 57, 1441-1452.

Pampoulie, C., 2001. Demographic structure and life history traits of the common goby Pomatoschistus microps (Teleostei, Gobiidae) in a Mediterranean coastal lagoon (Rhône River delta, France). Acta Oecologica 22 253-257.
Pardal, M.A., Marques, J.C., Bellan, G., 1993. Spatial distribution and seasonal variation of subtidal polychaete populations in the Mondego estuary (western Portugal). Cahiers de Biologie Marine 34, 497-512.

Pardal, M.A., Marques, J.C., Metelo, I., Lillebo, A.I., Flindt, M.R., 2000. Impact of eutrophication on the life cycle, population dynamics and production of Amphitoe valida (Amphipoda) along an estuarine spatial gradient (Mondego estuary, Portugal) 196, 207-219.

Pihl, L., 1985. Food selection and consumption of mobile epibenthic fauna in shallow marine areas. Marine Ecology Progress Series 22, 169-179.

Prista, N., Vasconselos, R.P., Costa, M.J., Cabral, H., 2003. The demersal fish assemblage of the coastal area adjacent to the Tagus estuary (Portugal): relationships with environmental conditions. Oceanologica Acta 26, 525-536.

Raffaelli, D., Milne, H., 1987. An experimental investigation of the effects of shorebird and flatfish predation on estuarine invertebrates. Estuarine, Coastal and Shelf Science 24, 1-13.

Raffaelli, D., Connacher, A., McLachlan, H., Emmes, C., 1989. The role of epibenthic crustacean predators in an estuarine food web. Estuarine, Coastal and Shelf Science 28, 149-160.

Ross, S.T., 1986a. Resource partitioning in ecological communities. Science $185,27-39$.

Ross, S.T., 1986b. Resource partitioning in fish assemblages: a review of field studies. Copeia 9, 352-388.

Rogers, S.I., 1988. Reproductive effort and efficiency in the female common goby. Pomatoschistus microps (Krøyer) (Teleostei: Gobioidei). Journal of Fish Biology 33, 109-119.

Salgado, J.P., Cabral, H.N., Costa, M.J., 2004. Feeding ecology of the gobies Pomatoschistus minutus (Pallas, 1770) and Pomatoschistus microps (Krøyer, 1838) in the upper Tagus estuary, Portugal. Scientia Marina 68, 425-434.

Ter Braak, C.J.F., 1988. CANOCO - A Fortran Program for Canonical Community Ordination by Partial Detrended Canonical Correspondence Analysis, Principal Components and Redundancy Analysis. Agricultural and Mathematical Group, Wageningen

Ter Braak, C.J.F., Prentice, I.C., 1988. A theory of gradient analysis. Advances in Ecological Research 18, 271-317.

Thorman, S., Wiederholm, A.M., 1983. Seasonal occurrence and food resource use of an assemblage of near shore fish in the Bothnian sea, Sweden. Marine Ecology Progress Series 10, 223-229.

Wallace, H., Ramsay, J.S., 1983. Ratability in measuring diet overlap. Canadian Journal of Fisheries and Aquatic Sciences 40, 347-351.

Wiederholm, A.-M., 1987. Distribution of Pomatoschistus minutus and P. microps (Gobiidae, Pisces) in the Bothnian sea: importance of salinity and temperature. Memoranda Societá Fauna Flora Fennica 63, 56-62.

Zander, C.D., 1990. Prey selection of the shallow water fish Pomatoschistus minutus (Gobiidae, Teleostei) in the SW Baltic. Helgoländer Meeresuntersuchungen $44,147-157$. 